\title{
Feasibility of Surgical Treatment for Laryngomalacia Using the Spontaneous Respiration Technique
}

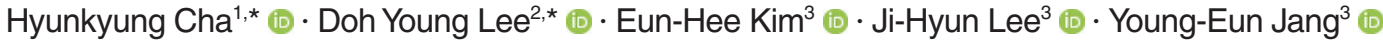 \\ Hee-Soo Kim ${ }^{3}$ (D) $\cdot$ Seong Keun Kwon ${ }^{1}$ [i]
}

'Department of Otorhinolaryngology-Head and Neck Surgery, Seoul National University Hospital, Seoul National University College of Medicine, Seoul; ${ }^{2}$ Department of Otorhinolaryngology-Head and Neck Surgery, SMG-SNU Boramae Medical Center, Seoul National University College of Medicine, Seoul; ${ }^{3}$ Department of Anesthesiology and Pain Medicine, Seoul National University Hospital, Seoul National University College of Medicine, Seoul, Korea

Objectives. In this study, we review our institutional experience with pediatric laryngomalacia (LM) and report our experiences of patients undergoing supraglottoplasty using the spontaneous respiration using intravenous anesthesia and high-flow nasal oxygen (STRIVE Hi) technique.

Methods. The medical records of 29 children with LM who visited Seoul National University Hospital between January 2017 and March 2019 were retrospectively reviewed. Surgical management was performed using the STRIVE Hi technique. Intraoperative findings and postoperative surgical outcomes, including complications and changes in symptoms and weight, were analyzed.

Results. Of the total study population of 29 subjects, 20 (68.9\%) were female. The patients were divided according to the Onley classification as follows: type I ( $n=13,44.8 \%)$, II $(n=10,34.5 \%)$, and III $(n=6,20.7 \%)$. Twenty-five patients (86.2\%) had comorbidities. Seventeen patients $(58.6 \%)$ underwent microlaryngobronchoscopy under STRIVE Hi anesthesia. Four patients with several desaturation events required rescue oxygenation by intermittent intubation and mask bagging during the STRIVE Hi technique. However, the procedure was completed in all patients without any severe adverse effects. Overall, 15 children (51.7\%) underwent supraglottoplasty, of whom 14 (93.3\%) showed symptom improvement, and their postoperative weight percentile significantly increased $(P=0.026)$. One patient required tracheostomy immediately after supraglottoplasty due to associated neurological disease.

Conclusion. The STRIVE Hi technique is feasible for supraglottoplasty in LM patients, while type III LM patients with micrognathia or glossoptosis may have a higher risk of requiring rescue oxygenation during the STRIVE Hi technique.

Keywords. Laryngomalacia; Airway Management; STRIVE Hi; Anesthesia; Surgical Procedure; Supraglottoplasty

\section{INTRODUCTION}

Laryngomalacia (LM) is the most common $(45 \%-75 \%)$ cause of congenital stridor, characterized by inward collapse of laryn-

- Received October 5, 2020

Revised December 4, 2020

Accepted January 8, 2021

- Corresponding author: Seong Keun Kwon

Department of Otorhinolaryngology-Head and Neck Surgery, Seoul National

University Hospital, 101 Daehak-ro, Jongno-gu, Seoul 03080, Korea

Tel: +82-2-2072-2286, Fax: +82-2-745-2387

E-mail: otolarynx@snuh.org

*These authors contributed equally to this work. geal structures, resulting in a narrow air passage and turbulent airflow that causes inspiratory stridor [1]. It generally worsens with feeding, crying, placing in the supine position, and agitation, and may lead to feeding problems, failure to thrive, and significant respiratory distress [2]. Olney et al. [1] categorized LM into three types according to the site of obstruction and the surgical procedure most likely to affect the outcome: type I, inward collapse of the aryepiglottic fold during inspiration; type II, long tubular epiglottis with short aryepiglottic folds; and type III, overhanging epiglottis that collapses posteriorly [3]. Diseases associated with LM include gastroesophageal reflux disease (65\%-100\%), congenital anomalies/syndromes ( $8 \%-20 \%)$, neu-

Copyright () 2021 by Korean Society of Otorhinolaryngology-Head and Neck Surgery.

This is an open-access article distributed under the terms of the Creative Commons Attribution Non-Commercial License (https://creativecommons.org/licenses/by-nc/4.0)

which permits unrestricted non-commercial use, distribution, and reproduction in any medium, provided the original work is properly cited. 
rological diseases $(20 \%-45 \%)$, cardiac diseases $(10 \%)$, and synchronous airway lesions (SALs; 7.5\%-64\%) [2].

Although most LM patients are managed with conservative medical therapy, patients with severe disease whose symptoms worsen despite treatment require surgical intervention under general anesthesia [4]. The conventional method using closed-circuit anesthesia with an endotracheal tube has several constraints for pediatric patients. Due to the small surgical field and anatomy of the pediatric airway and the thickness of the tube, endotracheal intubation results in the surgical field being covered by the tube, making it difficult to observe the surgical site and SAL in the lower airway [5]. For a wider surgical view, the intermittent apneic technique with jet ventilation was introduced for tubeless airway surgery. However, this technique requires repeated intubation, which is associated with risks of laryngeal injury, hypoxemia, and hypercapnia, and is a time-consuming procedure [5,6]. In addition, jet ventilation is associated with a risk of barotrauma due to high airway pressure $[5,7,8]$. Evaluating dynamic changes in the larynx of patients with LM is limited if a muscle relaxant is administered when performing anesthesia.

The spontaneous respiration using intravenous anesthesia and high-flow nasal oxygen (STRIVE Hi) technique is a tubeless, spontaneous-respiration anesthesia technique that uses total intravenous anesthesia in combination with high-flow nasal oxygen [8]. Using the tubeless self-respiration technique, we were able to evaluate dynamic obstruction of the upper airway in our patients, leading to an accurate diagnosis before performing supraglottoplasty. High-flow nasal oxygen has benefits with regard to prolonged apnea and reduction of the number of intermittent intubations [9]. The results of the procedure could be evaluated intraoperatively and further adjustments could be performed as necessary. A final dynamic evaluation of the surgical results was also possible using STRIVE Hi. This study investigated the characteristics of patients with LM who were referred to our tertiary hospital, and assessed the safety and efficacy of the STRIVE Hi technique and surgical outcomes of supraglottoplasty using this technique.

\section{H I I G H L L I}

- We analyzed the feasibility of the spontaneous respiration using intravenous anesthesia and high-flow nasal oxygen (STRIVE Hi) technique for the surgical management of laryngomalacia (LM).

- A relatively high proportion of LM patients in this study had multiple comorbidities.

- Approximately $73 \%$ of patients (13/17) did not need rescue oxygenation during the STRIVE Hi technique, and most of them $(93.3 \%)$ showed symptom improvement without any complications.

- Type III LM patients with micrognathia or glossoptosis may have a higher risk of requiring rescue oxygenation during the STRIVE Hi technique.

\section{MATERIALS AND METHODS}

\section{Subjects}

A retrospective review of medical records was performed for children with LM diagnosed and treated at Seoul National University Hospital from January 2017 to March 2019. Each subject underwent an evaluation that included history-taking, physical examination, and flexible laryngoscopy. Patients who were not followed up were excluded. The study population consisted of 29 patients diagnosed with LM by flexible laryngoscope examination. Type classification was performed based on the transnasal fiberoptic exam according to Olney's classification [1]. The study protocol was approved by the institutional review board of the Clinical Research Institute at Seoul National University Hospital (IRB No. 2004-226-1119). All methods were performed in accordance with the approved guidelines and the Declaration of Helsinki. All personal information was kept confidential as required.

\section{Surgical techniques}

Microlaryngobronchoscopy was considered for airway evaluation and accurate diagnosis in patients whose symptoms could not be controlled by conservative medical therapy. After conducting microlaryngobronchoscopy, the surgery, including supraglottoplasty, was determined as necessary. Indications for supraglottoplasty included severe airway obstruction presenting with significant chest retraction, bodyweight percentile $<5 \%$, or failure to thrive [10]. Surgery was performed by a single surgeon (SKK). Microlaryngobronchoscopy and supraglottoplasty were performed using the STRIVE Hi anesthesia technique. The main surgical technique used in this study for type I cases was making an incision on the short aryepiglottic fold and excising the redundant aryepiglottic fold (Fig. 1A). The posterior commissure mucosa was left untouched to avoid stenosis. For type II patients, the lateral side of the tubular epiglottis was vaporized in addition to the procedure for type I LM (Fig. 1B). For type III patients, epiglottopexy was performed using a $\mathrm{CO}_{2}$ laser to burn the mucosa of the tongue base and lingual surface of the epiglottis, and a suture was placed in between (Fig. 1C).

\section{STRIVE Hi anesthetic technique}

Starting with 3 minutes of preoxygenation, an AIRVO humidifier high-flow system (Fisher \& Paykel, Auckland, New Zealand) was used. The flow rate was set to $2 \mathrm{~L} / \mathrm{min} / \mathrm{kg}$ and the $\mathrm{FiO}_{2}$ was set to 1.0 and routinely reduced to $<0.3$ while using the $\mathrm{CO}_{2}$ laser. Intravenous (IV) $1 \%$ lidocaine and $1 \%$ propofol were administered during induction, and general anesthesia was maintained by IV infusion of propofol $(100-250 \mu \mathrm{g})$ and remifentanil $(0.01-0.1 \mu \mathrm{g} / \mathrm{kg} / \mathrm{min})$. The sedative infusion rate was maintained at a level to avoid undesirable events (patient movement, laryngotracheal spasm) while preserving the patient's self-respiration. Noninvasive blood pressure and pulse oximetry $\left(\mathrm{SpO}_{2}\right)$, as well 

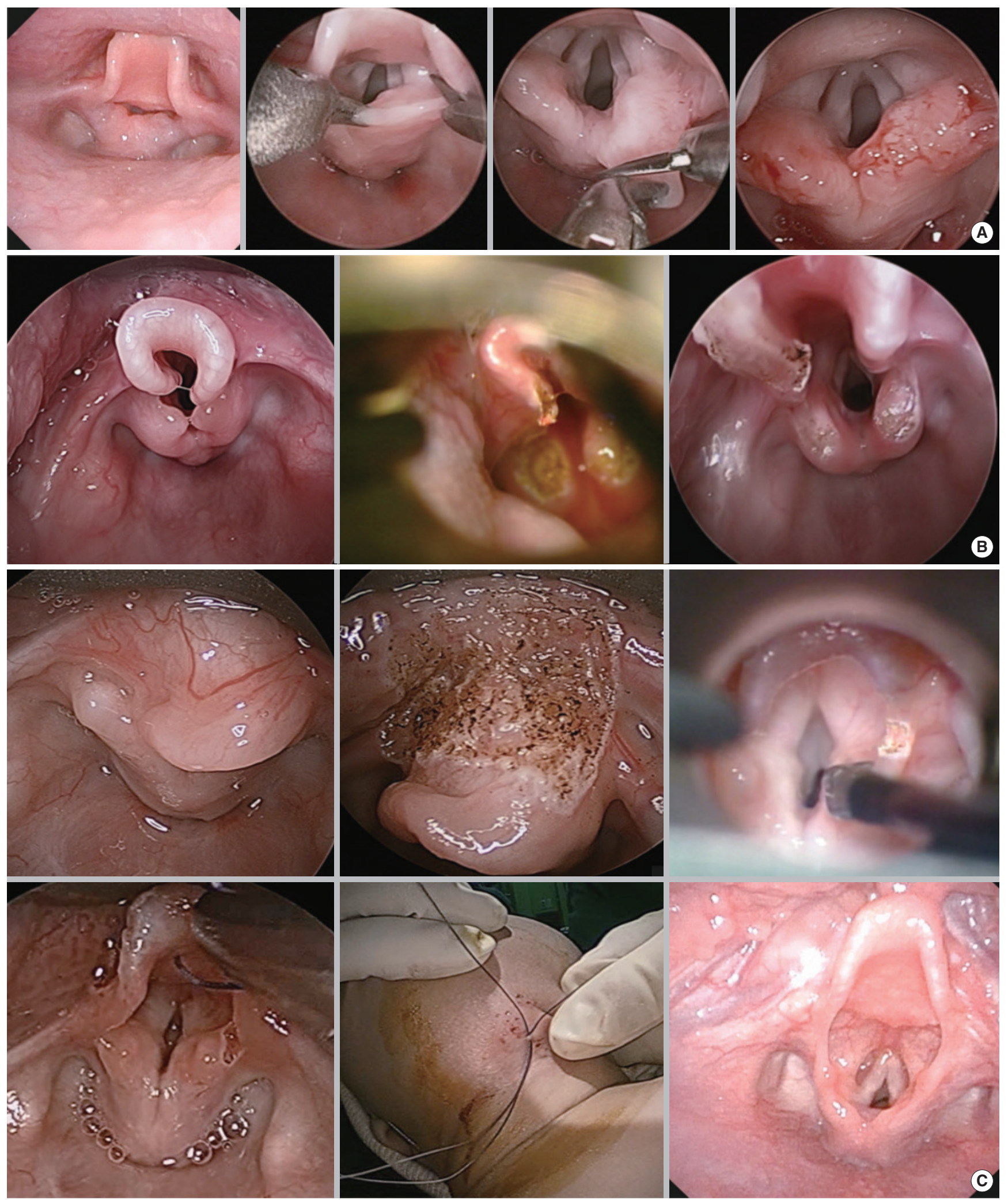

Fig. 1. Supraglottoplasty techniques for each type of laryngomalacia. (A) Type I, excision of short and redundant aryepiglottic fold. (B) Type II, lateral partial epiglottectomy in addition to the procedure used for type I. (C) Type III, excision of short aryepiglottic fold with epiglottopexy of after laser vaporization of epiglottis. 
as electrocardiography and oxygen reserve index (ORI) were monitored. A transcutaneous carbon dioxide $\left(\mathrm{TcCO}_{2}\right)$ monitor was attached to the right side of the chest instead of end-tidal carbon dioxide monitoring [5].

\section{Outcome criteria}

The patients' records were analyzed in terms of the age at which the LM was diagnosed, birth history, sex, symptoms, symptom onset, type according to Olney's classification, weight, and comorbid conditions. The feasibility of the STRIVE Hi anesthetic technique was evaluated according to the operation time, requirement for rescue oxygenation, and complications. Surgical outcomes, including resolution of symptoms, weight change, and complications, were also analyzed in patients who had undergone the operation. Weight percentile was analyzed using Wilcoxon's signed-rank test with IBM SPSS ver. 22.0 (IBM Corp., Armonk, NY, USA).

\section{RESULTS}

\section{Demographic and clinical data}

A total of $29 \mathrm{LM}$ patients were included in the study. The patients' characteristics are summarized in Table 1. Twenty $(68.9 \%)$ were female. Type I was the most common ( $n=13,44.8 \%)$, fol-

Table 1. Clinical characteristics of the patients

\begin{tabular}{lc}
\hline Variable & Number (\%) \\
\hline Sex (female:male) & $20(68.9): 9(31.1)$ \\
Type & \\
\hline I & $13(44.8)$ \\
III & $10(34.5)$ \\
Age of onset & $6(20.7)$ \\
At birth & $13(44.8)$ \\
$>1$ mo & $4(13.8)$ \\
$>2$ mo & $1(0.3)$ \\
Unknown & $11(37.9)$ \\
Symptom & \\
Respiratory symptom & \\
$\quad$ Stridor & $29(100)$ \\
$\quad$ Dyspnea with chest retraction & $16(55.2)$ \\
$\quad$ Stridor worsening with upper respiratory & $6(20.7)$ \\
$\quad$ infection or when crying, excited & \\
$\quad$ Cyanosis, tachypnea & $4(13.8)$ \\
Feeding symptom & $12(41.4)$ \\
$\quad$ Small feeding amount, dysphagia due to & \\
respiratory distress & $9(31.0)$ \\
Tube feeding (nasogastric or gastrostomy tube) & $7(24.1)$ \\
Vomiting when feeding & $6(20.7)$ \\
Aspiration & \\
Sleeping symptom & $6(20.7)$ \\
$\quad$ Snoring, apnea &
\end{tabular}

Table 2. Associated comorbidities

\begin{tabular}{|c|c|}
\hline Associated comorbidity & Number (\%) \\
\hline \multicolumn{2}{|l|}{ Congenital anomaly/syndrome/genetic disorder } \\
\hline Pierre Robin sequence & $1(3.4)$ \\
\hline Down syndrome & $1(3.4)$ \\
\hline Dandy-Walker (inversus) syndrome & $1(3.4)$ \\
\hline Trisomy 9 & $1(3.4)$ \\
\hline Cri du Chat variant & $1(3.4)$ \\
\hline Mobius syndrome & $1(3.4)$ \\
\hline \multicolumn{2}{|l|}{ Neurological disease } \\
\hline Seizure & $4(13.8)$ \\
\hline Developmental delay ${ }^{\mathrm{a})}$ & $4(13.8)$ \\
\hline Microcephaly, plagiocephaly $\left.{ }^{b}\right)$ & $3(10.3)$ \\
\hline Hypoxic ischemic encephalopathy & $3(10.3)$ \\
\hline Congenital hypotonia & $3(10.3)$ \\
\hline Others ${ }^{c)}$ & $2(6.9)$ \\
\hline \multicolumn{2}{|l|}{ Cardiac disease } \\
\hline ASD & $9(31.0)$ \\
\hline VSD & $4(13.8)$ \\
\hline PDA & $2(6.9)$ \\
\hline TOF & $2(6.9)$ \\
\hline TR & $1(3.4)$ \\
\hline PFO & $1(3.4)$ \\
\hline CMP & $1(3.4)$ \\
\hline \multicolumn{2}{|l|}{ Synchronous airway lesion } \\
\hline Micrognathia, retrognathia & $3(10.3)$ \\
\hline Subglottic stenosis & $3(10.3)$ \\
\hline Glossoptosis & $2(6.9)$ \\
\hline Tracheomalacia, bronchomalacia & $2(6.9)$ \\
\hline Tongue base or vallecular cyst & $2(6.9)$ \\
\hline Vocal fold palsy & $2(6.9)$ \\
\hline Cleft palate & $2(6.9)$ \\
\hline \multicolumn{2}{|l|}{ Musculoskeletal } \\
\hline Developmental dysplasia of the hip & $2(6.9)$ \\
\hline Kyphoscoliosis, T-spine & $1(3.4)$ \\
\hline A cyst in the filum terminale & $1(3.4)$ \\
\hline Partial agenesis of orbicularis oris muscle & $1(3.4)$ \\
\hline \multicolumn{2}{|l|}{ Ophthalmologic } \\
\hline Retinal disorder & $1(3.4)$ \\
\hline $\begin{array}{l}\text { Unilateral esotropia with secondary amblyopia and } \\
\text { bilateral optic neuropathy }\end{array}$ & $1(3.4)$ \\
\hline \multicolumn{2}{|l|}{ Kidney } \\
\hline Hydronephrosis & $3(10.3)$ \\
\hline \multicolumn{2}{|l|}{ Others } \\
\hline Mondini dysplasia, narrow BCNC (hearing loss) & $1(3.4)$ \\
\hline Neonatal hyperbilirubinemia & $4(13.8)$ \\
\hline $\begin{array}{l}\text { Disseminated intravascular coagulation, portal vein } \\
\text { thrombosis }\end{array}$ & $1(3.4)$ \\
\hline Neutropenia, aPTT prolongation & $1(3.4)$ \\
\hline BPD, RDS (hyaline membrane disease) & $3(10.3)$ \\
\hline
\end{tabular}

ASD, atrial septal defect; VSD, ventricular septal defect; PDA, patent ductus arteriosus; TOF, tetralogy of Fallot; TR, tricuspid regurgitation; PFO, patent foramen ovale; CMP, cardiomyopathy; $\mathrm{BCNC}$, bony cochlear nerve canal; aPTT, activated partial thromboplastin time; BPD, bronchopulmonary dysplasia; RDS, respiratory distress syndrome.

a)Language delay $(n=1)+$ global developmental delay $(n=3)$. ${ }^{\text {b) }}$ Plagiocephaly: microcephaly with simplified gyral pattern $(n=1)$. ${ }^{c}$ Cerebral infarct $(n=1)$, brain cyst $(n=1)$. 
lowed by type II ( $n=10,34.5 \%)$, and type III ( $n=6,20.7 \%)$. About half of the patients $(13,44.8 \%)$ had symptoms at birth. All patients presented with stridor. Dyspnea with chest retraction was the second most common symptom, followed by reduced feeding amount and dysphagia due to respiratory distress. Of the 29 patients, 26 (89.7\%) had comorbidities (Table 2). Among them, six patients $(20.7 \%)$ had congenital syndromes associated with multiple anomalies. Two children (33.3\%) with congenital anomalies/syndromes underwent supraglottoplasty. Of these, 11 (37.9\%) had neurological disorders. The most com- mon was seizure and developmental delay, and five (45.5\%) underwent supraglottoplasty. Thirteen children (44.8\%) had cardiac disease. The most common anomaly was atrial septal defect. Eight $(61.5 \%)$ of the patients with cardiac disease underwent supraglottoplasty and two (15.4\%) underwent heart surgery. One $(7.7 \%)$ underwent both procedures. SALs were found in $10(34.5 \%)$ patients and four $(40.0 \%)$ underwent supraglottoplasty. The most common SALs were micrognathia and retrognathia. Fourteen patients $(48.2 \%)$ had other comorbidities. Preoperatively, none had a patent tracheostoma.

Table 3. Perioperative characteristics of the patients who underwent surgical intervention

\begin{tabular}{|c|c|c|c|c|c|c|c|c|}
\hline No. & Sex & $\begin{array}{l}\text { Age } \\
(\mathrm{mo})\end{array}$ & Type & Comorbidity & Simultaneous airway lesion & Operation & $\begin{array}{l}\text { Operation } \\
\text { time }(\mathrm{min})^{\mathrm{a})}\end{array}$ & Rescue oxygenation \\
\hline 1 & M & 3.1 & I & - & - & $\begin{array}{l}\text { Microlaryngobronchoscopy+ } \\
\text { supraglottoplasty }\end{array}$ & 35 & - \\
\hline 2 & $\mathrm{~F}$ & 9.3 & I & $\mathrm{N} / \mathrm{S} / \mathrm{O}$ & Glossoptosis & $\begin{array}{c}\text { Microlaryngobronchoscopy+ } \\
\text { supraglottoplasty+tracheostomy }\end{array}$ & 55 & - \\
\hline 3 & $\mathrm{~F}$ & 2.6 & I & $\mathrm{G} / \mathrm{N} / \mathrm{C} / \mathrm{S}$ & $\begin{array}{l}\text { UVFP, tracheomalacia, } \\
\text { bronchomalacia }\end{array}$ & Microlaryngobronchoscopyc) & 30 & - \\
\hline 4 & $\mathrm{~F}$ & 4.1 & I & $\mathrm{G} / \mathrm{C} / \mathrm{S} / \mathrm{R}$ & Glossoptosis & $\begin{array}{l}\text { Microlaryngobronchoscopy+ } \\
\text { supraglottoplasty }\end{array}$ & 145 & Orotracheal intubation \\
\hline 5 & $\mathrm{~F}$ & 3.4 & II & $\mathrm{G} / \mathrm{N} / \mathrm{S} /$ & SGS, grade I & $\begin{array}{c}\text { Microlaryngobronchoscopy+ } \\
\text { supraglottoplasty }\end{array}$ & 30 & - \\
\hline 6 & $\mathrm{~F}$ & 3.3 & $\|$ & $\mathrm{C} / \mathrm{S} / \mathrm{O}$ & SGS, grade II & $\begin{array}{l}\text { Microlaryngobronchoscopy+ } \\
\text { supraglottoplasty }\end{array}$ & 66 & - \\
\hline 7 & $\mathrm{~F}$ & 3.9 & II & $\mathrm{O}$ & - & $\begin{array}{l}\text { Microlaryngobronchoscopy+ } \\
\text { supraglottoplasty }\end{array}$ & 50 & - \\
\hline 8 & M & 2.9 & $\|$ & $\mathrm{M} / \mathrm{O}$ & - & $\begin{array}{c}\text { Microlaryngobronchoscopy+ } \\
\text { supraglottoplasty }\end{array}$ & 60 & - \\
\hline 9 & M & 4.1 & II & $\mathrm{N} / \mathrm{C} / \mathrm{O}$ & - & $\begin{array}{l}\text { Microlaryngobronchoscopy+ } \\
\text { supraglottoplasty }\end{array}$ & 75 & - \\
\hline 10 & $\mathrm{~F}$ & 7.2 & ॥ & $\mathrm{C} / \mathrm{O}$ & - & $\begin{array}{l}\text { Microlaryngobronchoscopy+ } \\
\text { supraglottoplasty }\end{array}$ & 70 & - \\
\hline 11 & $\mathrm{~F}$ & 15.2 & II & $\mathrm{G} / \mathrm{N} / \mathrm{C} / \mathrm{S}$ & Vallecular cyst, SGS, grade II & $\begin{array}{l}\text { Microlaryngobronchoscopy+ } \\
\text { supraglottoplasty+ } \\
\text { vallecular cyst laser excision }\end{array}$ & 60 & - \\
\hline 12 & M & 19.9 & $\|$ & $\mathrm{N} / \mathrm{C} / \mathrm{R}$ & - & $\begin{array}{l}\text { Microlaryngobronchoscopy+ } \\
\text { supraglottoplasty }\end{array}$ & 75 & - \\
\hline 13 & $\mathrm{~F}$ & 2.5 & III & C & - & $\begin{array}{l}\text { Microlaryngobronchoscopy+ } \\
\text { supraglottoplasty }\end{array}$ & 140 & - \\
\hline 14 & $\mathrm{~F}$ & 19.0 & III & N & - & $\begin{array}{l}\text { Microlaryngobronchoscopy+ } \\
\text { supraglottoplasty }\end{array}$ & 15 & $\begin{array}{c}\text { Orotracheal intubation } \\
\text { (due to muscle relaxant } \\
\text { application for severe trismus) }\end{array}$ \\
\hline 15 & $\mathrm{~F}$ & 1.7 & III & $\mathrm{G} / \mathrm{C} / \mathrm{S}$ & $\begin{array}{l}\text { Micrognathia, retrognathia, cleft } \\
\text { palate, bronchomalacia }\end{array}$ & Microlaryngobronchoscopy & 60 & Intermittent mask bagging \\
\hline 16 & $\mathrm{~F}$ & 3.4 & III & $\mathrm{C} / \mathrm{S} / \mathrm{O}$ & Micrognathia, tongue base cyst & $\begin{array}{c}\text { Microlaryngobronchoscopy+ } \\
\text { supraglottoplasty+ } \\
\text { tongue base cyst excision }\end{array}$ & 35 & Orotracheal intubation \\
\hline 17 & M & 1.9 & III & S & $\begin{array}{l}\text { Micrognathia, glossoptosis, } \\
\text { tongue base cyst }\end{array}$ & $\begin{array}{c}\text { Microlaryngobronchoscopy+ } \\
\text { supraglottoplasty+ } \\
\text { tongue base cyst excision }\end{array}$ & 80 & Orotracheal intubation \\
\hline
\end{tabular}

N, neurological disease; S, synchronous airway lesion; O, ophthalmological; G, genetic disorders; C, cardiac disease; R, renal; O, others; M, musculoskeletal; uVFP, unilateral vocal fold palsy; SGS, subglottic stenosis.

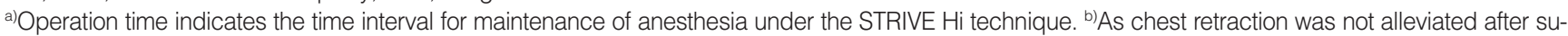
praglottoplasty, the surgeon decided to perform tracheostomy after conversion to orotracheal intubation. There was no need for rescue oxygenation during supraglottoplasty. ${ }^{\text {c)}}$ Cases with planned tracheostomy. 


\section{Patients with surgical intervention}

A total of 17 children (58.6\%) underwent microlaryngobronchoscopy, 15 of whom continued to undergo supraglottoplasty under STRIVE Hi anesthesia (Table 3). Most type I patients did not require surgical intervention (4 of 13 patients required supraglottoplasty or tracheostomy, 30.8\%). By contrast, most of the type II and III patients required surgery, including supraglottoplasty or tracheostomy $(8 / 10,80 \%$ vs. $5 / 6,83.3 \%$, respectively). Tracheostomy was planned for the remaining two patients without supraglottoplasty. Of these, one with micrognathia underwent tracheostomy (case 15), and the other patient with tracheomalacia and bronchomalacia did not undergo tracheostomy due to parental disagreement (case 3), and the symptoms improved slightly after 1 year of follow-up.

\section{STRIVE Hi anesthesia maintenance and requirement for rescue oxygenation}

The average age at the operation using the STRIVE Hi technique was 6 months (standard deviation [SD], 5.9 months; range, 1-20 months). Twelve patients (70.6\%) completed the diagnostic procedure and surgical intervention without desaturation events (Fig. 2). The overall lowest $\mathrm{SpO}_{2}$ was $75 \%$ (mean \pm SD, 86.53\% \pm $12.17 \%$; median, $88 \%$ ) and the highest $\mathrm{TcCO}_{2}$ was $75.2 \mathrm{mmHg}$ (mean \pm SD, $64.83 \pm 10.70 \mathrm{mmHg}$; median, $69.2 \mathrm{mmHg}$ ). The mean self-ventilation maintenance time was 63.6 minutes (range, 15-145 minutes). The STRIVE Hi technique could not be main- tained in one patient because of the requirement for muscle relaxation agents due to severe trismus. Desaturation events under the STRIVE Hi technique occurred in four cases, which ultimately led to conversion to conventional intubation in three cases, while the other was assisted with intermittent mask bagging (Table 3). The three patients in whom conversion to conventional intubation was performed had SALs, such as glossoptosis, tongue base cyst, and micrognathia. In one case, intermittent desaturation events occurred during the operation, which were assisted by intermittent mask bagging while maintaining the STRIVE Hi technique. In all cases, surgery was completed without any complications.

As the larynx could swell immediately after surgery, all patients were routinely administered epinephrine and inhaled salbutamol via a nebulizer. After supraglottoplasty, a high-flow nasal cannula was used in four patients $(4 / 15,28.6 \%)$ and eight patients $(8 / 15,57.1 \%)$ were monitored in the intensive care unit postoperatively. All patients were transferred to the general ward within 24 hours.

\section{Surgical outcomes}

Because the most of the patients were admitted to Department of Pediatrics, daily follow-up of symptoms was possible for 1 or 2 weeks after the operation. Symptoms usually improved on postoperative day 1 or 2 after the mucosal edema subsided. Symptom improvement was observed in $14(93.3 \%)$ of the 15

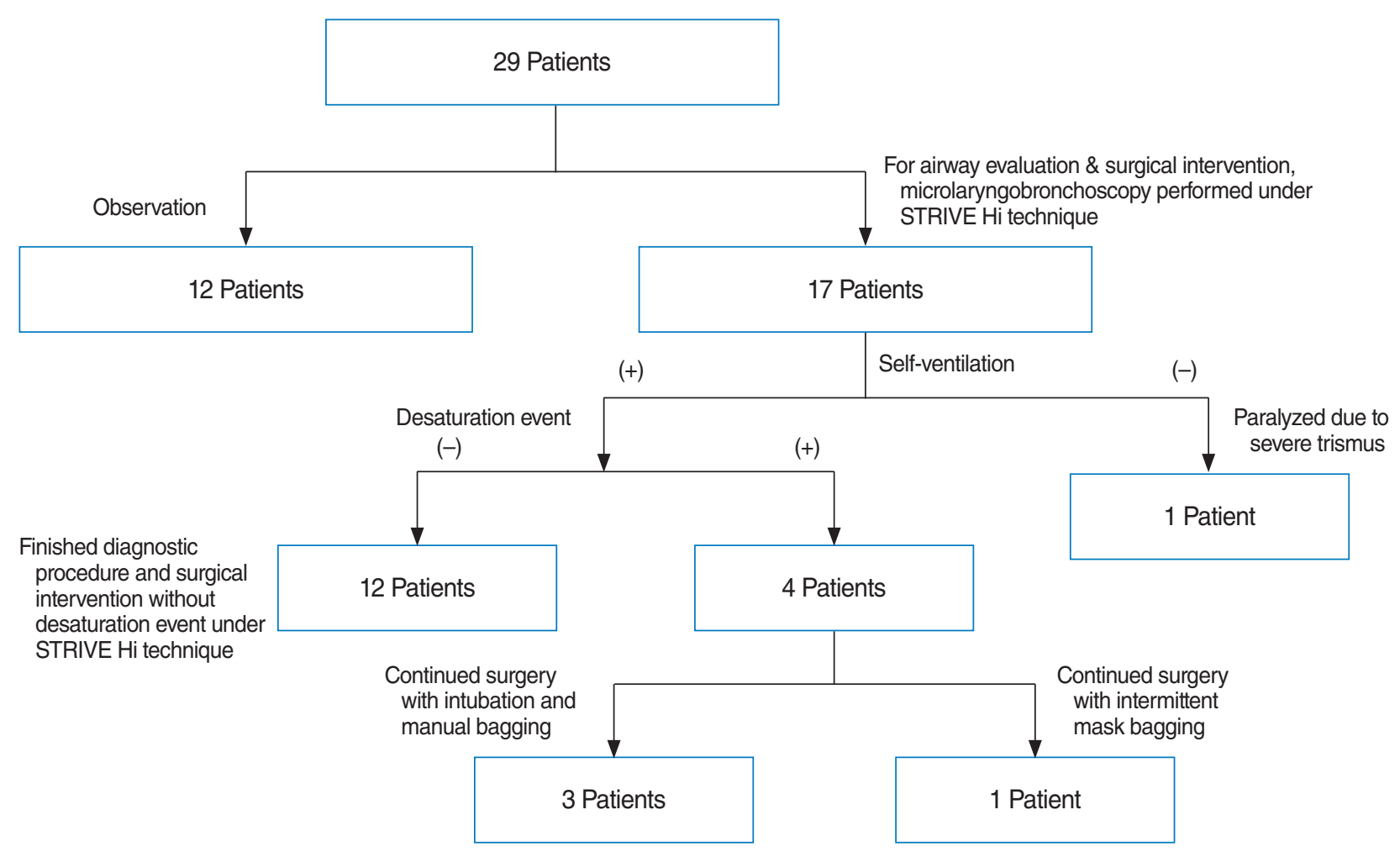

Fig. 2. Flowchart for anesthesia maintenance and events. 


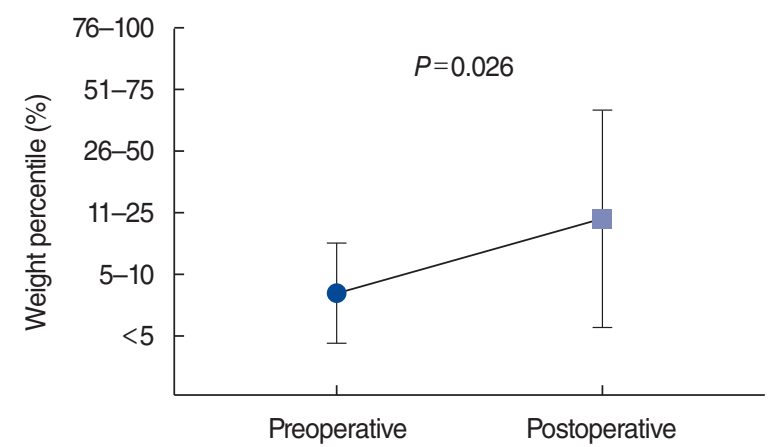

Fig. 3. Weight percentile change after surgery. Patients with supraglottoplasty showed significant changes in weight percentile $(P=$ 0.026).

children who underwent supraglottoplasty. Weight percentile changes were analyzed for 11 children for whom data were available, and the weight percentile was found to increase significantly postoperatively (Wilcoxon's signed-rank test, $P=0.026$ ) (Fig. 3).

Only one patient showed aggravated inspiratory stridor and suprasternal retraction after supraglottoplasty. This patient had multiple brain anomalies (global developmental delay secondary to hypoxic ischemic encephalopathy, bilateral brain infarcts, microcephaly, seizure) and SAL (glossoptosis), which aggravated symptoms after supraglottoplasty. The surgeon determined that tracheostomy was necessary based on observations of the patient's respiratory pattern and airway dynamics under STRIVE Hi anesthesia.

\section{DISCUSSION}

Patients with LM who were referred to or detected at the authors' tertiary hospital included a higher proportion of type II and III cases. Most had one or multiple comorbidities and airway lesions. For LM patients, the STRIVE Hi technique may be useful and feasible for both microlaryngobronchoscopy and supraglottoplasty. In this study, $70.6 \%$ of patients (12/17) underwent microlaryngobronchoscopy with or without supraglottoplasty under the STRIVE Hi technique without any support from other anesthetic types of oxygen supply. The STRIVE Hi technique may have the potential for failure in patients with multiple comorbidities, particularly SAL.

The clinical characteristics of the patients in our study showed discrepancies from previous research. Inspiratory stridor in patients with LM is typically present during the first 2-4 weeks of life, and worsens with feeding, crying, placement in the supine position, and agitation [10]. It usually deteriorates over the first 6 months of life, with symptoms resolving in most patients $(\sim 70 \%)$ by the age of 24 months [11]. However, almost half of the patients $(13,43.3 \%)$ at our institution showed symptoms from birth. The symptoms in LM patients are generally managed with conservative and medical therapy [4]. Despite the primarily spontaneously resolving nature of LM, 51.7\% (15/29) of patients with LM and $61.5 \%$ (8/13) of patients with both LM and cardiac disease underwent supraglottoplasty at our center. This proportion is higher than in previous reports $(12 \%-31 \%$ and $34 \%$, respectively) [1,4,12-14].

The proportion of cases undergoing surgical treatment in our study was higher than that reported in previous studies because we had a higher proportion of patients with comorbidities and type II/III LM according to Onley's classification. In previous studies, the rates of associated syndromes were $8 \%-20 \%$, neurological disorders were $20 \%-45 \%$, cardiac diseases were $\sim 10 \%$, and SAL were $7.5 \%-64 \%$ [1,15-17]. One of the most common features of SAL is the presence of other types of airway malacia, such as tracheomalacia and/or bronchomalacia $(2 \%-48 \%)[1,3$, $11,15]$, and another common SAL is facial malformation (micrognathia and retrognathia, 10.3\%). The presence of associated diseases increases the risk for negative outcomes after supraglottoplasty and the likelihood of performing tracheostomy [13,18]. In our study, the prevalence of comorbidities was similar to or higher than in previous studies (syndromes, neurological disorders, cardiac diseases, and SAL: 20\%, 40\%, 46.7\%, and 36.7\%, respectively). Another reason for the higher rate of surgical cases may have been the relatively high rates of type II and III LM in our cohort (type I, 43.3\%; type II, 30\%; type III, 23.3\%). Olney et al. [1] reported that $57 \%$ of patients had type I LM, $15 \%$ had type II, 13\% had type III, and 15 had combined types. According to the study, most patients with type I did not require surgery. By contrast, most type II/III LM patients required surgery, suggesting that type I may be a milder form than type II/III.

There are six possible anesthetic methods that can supply adequate oxygen during airway management: spontaneous breathing; positive pressure ventilation via an endotracheal tube; jet ventilation; apneic oxygenation using humidified high-flow nasal oxygen delivery systems or intermittent ventilation; crossfield ventilation; and extracorporeal membrane oxygenation (ECMO)/cardiopulmonary bypass (CPB) [19]. In the conventional endotracheal tube ventilation technique, the tube hides the subglottic airway and the surgical field. Sometimes, a tube can be intermittently withdrawn and excision can be performed while the child is apneic [2]. However, the process of inserting and removing the tube can cause airway trauma and prolong the operation time. The apneic technique with intermittent ventilation allows only approximately 3 minutes until further ventilation and oxygenation for a 3- to 4-year-old child [20,21]. In cases with associated conditions, such as cardiac, pulmonary, and airway lesions, which can affect cardiac output, the time to desaturation is likely to be even shorter [21,22]. The jet ventilation technique provides a tubeless surgical field. However, it has several disadvantages associated with the high airway pressure, such as an elevated risk for barotrauma (including pneumotho- 
rax, pneumomediastinum, and subcutaneous emphysema) and low reliability of end-tidal $\mathrm{CO}_{2}$ monitoring [19]. The cross-field ventilation technique requires tracheostomy, and $\mathrm{ECMO} / \mathrm{CPB}$ is indicated in open surgery when manipulation of the heart and the great vessels is planned. The STRIVE Hi technique is a tubeless self-respiratory anesthesia method maintained intravenously, while additional oxygen and ventilation are supplied by a high-flow nasal cannula $[9,23]$. The high-flow nasal cannula allows oxygen delivery without the presence of any equipment in the surgical field and airway. In addition, it minimizes interruptions for rescue oxygenation even in settings of apnea or hypoventilation [24]. However, as mentioned, desaturation events occurred in four cases, which led to the requirement for oxygenation rescue [5]. Monitoring of ORI with $\mathrm{SpO}_{2}$ provides an early warning before oxygen saturation begins to decrease, which helps to avoid unanticipated hypoxia events [25]. By checking the ORI and $\mathrm{SpO}_{2}$ value, the anesthesiologists anticipated hypoxia, recognized the need to perform oxygenation rescue at the appropriate time, and finished preoxygenation without hyperoxia. All oxygen rescue processes were continued with sufficient multidisciplinary communication. When an anesthesiologist notified the team of signs of desaturation, the operation was stopped and temporary tracheal intubation was performed through a Benjamin-Lindholm laryngoscope. Likewise, continuous $\mathrm{CO}_{2}$ monitoring is essential because the elevation of $\mathrm{CO}_{2}$ needs correction during the operation. Mask bagging was performed by an anesthesiologist. As a result, all operations were completed without severe adverse events while intubation was performed in three cases and intermittent mask bagging was performed in one case (Table 3). In another case in which the patient did not have SAL, oxygen saturation was stable with the STRIVE Hi technique. However, a muscle relaxant had to be applied because the surgical site could not be exposed due to severe trismus, which led to the loss of self-respiration and conversion to conventional intubation. After experiencing several cases with the STRIVE Hi technique, we would suggest that this technique is contraindicated for patients with a skull base fracture or choanal atresia. In addition, poor exposure of the surgical field, such as in cases of micrognathia, is a relative contraindication of transoral supraglottoplasty under the STRIVE Hi technique.

During the operation using the STRIVE Hi technique, temperature and humidity were maintained uniformly for all patients at levels that were high enough to prevent feelings of dryness in the nasal cavity of patients and to promote tolerance for the high-flow rate [26]. In addition, higher temperature and humidity than the gas supplied in conventional anesthesia can decrease intraoperative oxygen demand by maintaining body temperature higher [27], and postoperative lung complications may decrease by maintaining the mucociliary clearance of the airway [28]. The flow rate of $\mathrm{O}_{2}$ was $2 \mathrm{~L} / \mathrm{min} / \mathrm{kg}$ according to previous reports and experiences at our institution [5]. There were no complications associated with the use of the STRIVE Hi tech- nique such as pneumothorax, gastrointestinal air, or difficulty obtaining a seal during masking. There was no fire when we used a $\mathrm{CO}_{2}$ laser under the STRIVE Hi technique, probably due to the lack of a medium to support ignition such as an endotracheal tube.

LM is suspected based on a typical clinical history, but the diagnosis is confirmed by a flexible fiberoptic exam in conscious patients [10]. Sivan et al. [29] reported that anesthesia/sedationaided diagnosis may sometimes be more accurate than conscious examination due to rapid laryngeal motion and lack of patient cooperation. Patients with severe LM may be at greater risk for SALs causing multilevel airway obstruction $[2,16]$. This supports the importance of conducting microlaryngobronchoscopy for a multilevel airway assessment before supraglottoplasty. Using the STRIVE Hi technique, we could secure the surgeon's view without blocking the endotracheal tube and perform accurate preoperative evaluation of airway dynamics. During supraglottoplasty, movements of the supraglottis did not hinder the surgical procedure as the surgical site was immobilized with cup forceps or alligator forceps. The postoperative outcome could be checked in real-time during supraglottoplasty, and the surgeon could decide whether the patient required tracheostomy before leaving the operating room.

The success rate of supraglottoplasty is approximately $94 \%$, and it has a low complication rate. In this study, using the STRIVE Hi technique, 93.3\% (14/15) of patients who underwent supraglottoplasty showed symptom improvement without severe complications. Children with LM are at significant risk for insufficient weight gain due to an increased workload while breathing and increased energy expenditure [3]. The most frequent reasons for surgical intervention are worsening airway symptoms and failure to thrive [30]. Similarly, the most important indicator of the improvement of LM in infants is appropriate weight gain [3]. Our patients showed significant changes in weight percentile after supraglottoplasty $(P=0.026)$.

Patients with LM referred to our tertiary hospital had higher comorbidity rates than previously reported. Supraglottoplasty is a safe and effective treatment for most cases of severe LM. The STRIVE Hi technique ensures that the surgeon has an appropriate view for accurate diagnosis and ease of operation, and enables evaluation of the immediate postoperative respiratory status and results. Type III LM patients with micrognathia or glossoptosis may have a higher likelihood of requiring rescue oxygenation during the STRIVE Hi technique, while the presence of multiple comorbidities seemed to have no effect on the surgical success of supraglottoplasty.

\section{CONFLICT OF INTEREST}

No potential conflict of interest relevant to this article was reported. 


\section{ACKNOWLEDGMENTS}

This research was supported by the Bio \& Medical Technology Development Program of the National Research Foundation (NRF) funded by the Korean government (MSIT) (No. 2019M3A9H1103617). Also, This research was supported by a grant of the Korea Health Technology R\&D Project through the Korea Health Industry Development Institute (KHIDI), funded by the Ministry of Health \& Welfare, Republic of Korea (grant number: HI14C1277).

\section{ORCID}

Hyunkyung Cha

https://orcid.org/0000-0002-3462-3789

Doh Young Lee

https://orcid.org/0000-0003-1590-8559

Eun-Hee Kim

https://orcid.org/0000-0003-0697-1935

Ji-Hyun Lee

https://orcid.org/0000-0002-8384-8191

Young-Eun Jang

https://orcid.org/0000-0002-7511-4104

Hee-Soo Kim

https://orcid.org/0000-0002-2661-7944

Seong Keun Kwon

\section{AUTHOR CONTRIBUTIONS}

Conceptualization: HSK, SKK. Data curation: HC, EHK, JHL, YEJ, HSK, SKK. Formal analysis: HC, DYL, SKK. Methodology: EHK, JHL, YEJ, HSK, SKK. Visualization: HC, DYL, SKK. Writing-original draft: HC, DYL, SKK. Writing-review \& editing: SKK.

\section{REFERENCES}

1. Olney DR, Greinwald JH Jr, Smith RJ, Bauman NM. Laryngomalacia and itstreatment. Laryngoscope. 1999 Nov;109(11):1770-5.

2. Bedwell J, Zalzal G. Laryngomalacia. Semin Pediatr Surg. 2016 Jun; 25(3):119-22.

3. Kusak B, Cichocka-Jarosz E, Jedynak-Wasowicz U, Lis G. Types of laryngomalacia in children: interrelationship between clinical course and comorbid conditions. Eur Arch Otorhinolaryngol. 2017 Mar; 274(3):1577-83.

4. Thompson DM. Abnormal sensorimotor integrative function of the larynx in congenital laryngomalacia: a new theory of etiology. Laryngoscope. 2007 Jun;117(6 Pt 2 Suppl 114):1-33.

5. Ji JY, Kim EH, Lee JH, Jang YE, Kim HS, Kwon SK. Pediatric airway surgery under spontaneous respiration using high-flow nasal oxygen. Int J Pediatr Otorhinolaryngol. 2020 Jul;134:110042.

6. Jaquet Y, Monnier P, Van Melle G, Ravussin P, Spahn DR, CholletRivier M. Complications of different ventilation strategies in endoscopic laryngeal surgery: a 10-year review. Anesthesiology. 2006 Jan; 104(1):52-9.

7. CraftTM, Chambers PH,Ward ME, Goat VA. Two cases of barotrauma associated with transtracheal jet ventilation. Br J Anaesth. 1990 Apr;64(4):524-7.

8. Booth AW,Vidhani K, Lee PK, Thomsett CM. SponTaneous Respira-

tion using IntraVEnous anaesthesia and Hi-flow nasal oxygen (STRIVE Hi) maintains oxygenation and airway patency during management of the obstructed airway: an observational study. Br J Anaesth. 2017 Mar;118(3):444-51.

9. Riva T, Seiler S, Stucki F, Greif R, Theiler L. High-flow nasal cannula therapy and apnea time in laryngeal surgery. Paediatr Anaesth. 2016 Dec;26(12):1206-8.

10. Ayari S, Aubertin G, Girschig H, Van Den Abbeele T, Mondain M. Pathophysiology and diagnostic approach to laryngomalacia in infants. Eur Ann Otorhinolaryngol Head Neck Dis. 2012 Oct;129(5): 257-63.

11. Krashin E, Ben-Ari J, Springer C, Derowe A, Avital A, Sivan Y. Synchronous airway lesions in laryngomalacia. Int J Pediatr Otorhinolaryngol. 2008 Apr;72(4):501-7.

12. Roger G, Denoyelle F, Triglia JM, Garabedian EN. Severe laryngomalacia: surgical indications and results in 115 patients. Laryngoscope. 1995 Oct;105(10):1111-7.

13. Hoff SR, Schroeder JW Jr, Rastatter JC, Holinger LD. Supraglottoplasty outcomes in relation to age and comorbid conditions. Int $\mathrm{J}$ Pediatr Otorhinolaryngol. 2010 Mar;74(3):245-9.

14. Thompson DM. Laryngomalacia: factors that influence disease severity and outcomes of management. Curr Opin Otolaryngol Head Neck Surg. 2010 Dec;18(6):564-70.

15. Dickson JM, Richter GT, Meinzen-Derr J, Rutter MJ,Thompson DM. Secondary airway lesions in infants with laryngomalacia. Ann Otol Rhinol Laryngol. 2009 Jan;118(1):37-43.

16. Schroeder JW Jr, Bhandarkar ND, Holinger LD. Synchronous airway lesions and outcomes in infants with severe laryngomalacia requiring supraglottoplasty. Arch Otolaryngol Head Neck Surg. 2009 Jul;135(7): 647-51.

17. Yuen HW, Tan HK, Balakrishnan A. Synchronous airway lesions and associated anomalies in children with laryngomalacia evaluated with rigid endoscopy. Int J Pediatr Otorhinolaryngol. 2006 Oct;70(10): 1779-84.

18. Escher A, Probst R, Gysin C. Management of laryngomalacia in children with congenital syndrome: the role of supraglottoplasty. J Pediatr Surg. 2015 Apr;50(4):519-23.

19. Bradley J, Lee GS, Peyton J.Anesthesia for shared airway surgery in children. Paediatr Anaesth. 2020 Mar;30(3):288-95.

20. Weisberger EC, Emhardt JD. Apneic anesthesia with intermittent ventilation for microsurgery of the upper airway. Laryngoscope. 1996 Sep;106(9 Pt 1):1099-102.

21. Gleason JM, Christian BR, Barton ED. Nasal cannula apneic oxygenation prevents desaturation during endotracheal intubation: an integrative literature review.West J Emerg Med. 2018 Mar;19(2):403-11.

22. Grubler MR, Wigger O, Berger D, Blochlinger S. Basic concepts of heart-lung interactions during mechanical ventilation. Swiss Med Wkly. 2017 Sep;147:w14491.

23. Gustafsson IM, Lodenius A, Tunelli J, Ullman J, Jonsson Fagerlund M. Apnoeic oxygenation in adults under general anaesthesia using Transnasal Humidified Rapid-Insufflation Ventilatory Exchange (THRIVE): a physiological study. Br J Anaesth. 2017 Apr;118(4):610-7.

24. Humphreys S, Rosen D, Housden T, Taylor J, Schibler A. Nasal highflow oxygen delivery in children with abnormal airways. Paediatr Anaesth. 2017 Jun;27(6):616-20.

25. Scheeren TW, Belda FJ, Perel A. The oxygen reserve index (ORI): a new tool to monitor oxygen therapy. J Clin Monit Comput. 2018 Jun;32(3):379-89.

26. Renda T, Corrado A, Iskandar G, Pelaia G, Abdalla K, Navalesi P. High-flow nasal oxygen therapy in intensive care and anaesthesia. Br J Anaesth. 2018 Jan;120(1):18-27.

27. Walczynska A, Sobczyk L. The underestimated role of temperatureoxygen relationship in large-scale studies on size-to-temperature response. Ecol Evol. 2017 Aug;7(18):7434-41. 
28. Kilgour E, Rankin N, Ryan S, Pack R. Mucociliary function deteriorates in the clinical range of inspired air temperature and humidity. Intensive Care Med. 2004 Jul;30(7):1491-4.

29. Sivan Y, Ben-Ari J, Soferman R, DeRowe A. Diagnosis of laryngomalacia by fiberoptic endoscopy: awake compared with anesthesia-aid- ed technique. Chest. 2006 Nov;130(5):1412-8.

30. RamprasadVH, Ryan MA, Farjat AE, Eapen RJ, Raynor EM. Practice patterns in supraglottoplasty and perioperative care. Int J Pediatr Otorhinolaryngol. 2016 Jul;86:118-23. 